Çukurova Üniversitesi Mühendislik Mimarlık Fakültesi Dergisi, 35(1), ss. 1-10, Mart 2020

Çukurova University Journal of the Faculty of Engineering and Architecture, 35(1), pp. 1-10, March 2020

\title{
Ürgüp Bölgesinde Olasılık Dağılımları ile GaAs Tip PV Enerji Üretim Potansiyelinin Modellenmesi
}

\author{
İlker MERT ${ }^{* 1}$ \\ ${ }^{1}$ Osmaniye Korkut Ata Üniversitesi, Osmaniye Meslek Yüksekokulu, Elektrik ve Enerji Bölümü, \\ Osmaniye
}

Geliş tarihi: 26.09.2019 Kabul tarihi: 15.05 .2020

\section{$\ddot{\mathbf{O} z}$}

Ürgüp Türkiye'nin önemli turizm çekim merkezlerinden biridir. Turizm sektöründe tesislerin yüksek enerji çeken havalandırma, çamaşırhane ve soğuk depoları gibi birimlerinde tüketilen enerjiyi karşılamak amacıyla fotovoltaik (Solar-PV) sistemlerin kullanımı giderek yaygınlaşmaktadır. Bu manada önemli turizm noktalarından biri olan Ürgüp bölgesinde faaliyet gösteren turizm tesisleri ve bu konuda yatırım yapmak isteyen yatırımcılar için bölgenin PV panellerden elektrik enerjisi üretimi potansiyelinin belirlenmesi son derece önemlidir. Bu çalışmada Weibull ve Lognormal dağılımları ile Ürgüp bölgesinin güneş ışınımı verileri kullanılarak olasılık yoğunluk fonksiyonu yaklaşımı tabanlı GaAs Tip PV elektrik enerjisi potansiyelinin modellenmesi amaçlanmıştır.

Anahtar Kelimeler: Weibull dağılımı, Lognormal dağılım, Güneş ışııımı, GaAs Tip PV

\section{Modeling of GaAs Type PV Energy Production Potential with Probability Distributions in the Ürgüp Region}

\begin{abstract}
Ürgüp is one of the major tourist attractions in Turkey. In the tourism sector, the use of photovoltaic systems is becoming widespread in order to meet the energy consumed in the units of the facilities such as ventilation, laundry and cold storage areas which attract high energy. In this sense, for the tourism facilities operating in the Ürgüp region, which is one of the important tourism points, and for investors who want to invest in this field, it is extremely important to determine the electricity generation potential of the region from photovoltaic panels. In this study, it is aimed to model photovoltaic electric energy potential based on probability density function approach with Weibull and Lognormal distributions by using solar radiation data of Ürgüp region.
\end{abstract}

Keywords: Weibull distribution, Lognormal distribution, Solar radiation, GaAs Type PV

*Sorumlu yazar (Corresponding author): İlker MERT, ilkermert@osmaniye.edu.tr 


\section{GíRiş}

Yenilenebilir enerji kaynağı olarak güneş enerjisinden elektrik üretimi amaciyla yapılan güneş enerjisi santrali (GES) yatırımları giderek artmaktadır. Coğrafi konumu nedeniyle birçok ülkeye göre çok daha kullanışı ve verimli alanlara sahip olan Türkiye'nin güneş enerjisi potansiyelinin yüksek olması fotovoltaik (SolarPV) sistemlere olan ilgiyi artırmaktadır. GES yatırımının kuruluş izinlerinin kolay bir şekilde alınabilmesi ve devletin sağladığı teşvik-destekler girişimcileri GES kurmaya yöneltmektedir. Ayrıca GES'lerin ilk yatırım tutarında önemli bir kısmı oluşturan panel maliyetlerinin giderek düşmesi ve işletme döneminde karlılığ 1 önemli oranda artıran panel verimlerinin artması gibi faktörler de GES yatırımı cazibesini artırmaktadır.

Coğrafi konumu açısından yüksek güneş enerjisi potansiyeline sahip ülkelerden biri olan Türkiye'nin en fazla ve en çok güneş alan bölgesi Güneydoğu Anadolu Bölgesi'dir. Ardından Akdeniz Bölgesi, Doğu Anadolu bölgesi ve İç Anadolu bölgesi gelmektedir.

Ürgüp, İç Anadolu Bölgesinde Nevşehir İli’nin doğusunda yer almaktadır. Nevşehir yıllık yaklaşık $1560 \mathrm{kWh} / \mathrm{m}^{2}$ 'lik güneş 1şınımı değeriyle önemli bir potansiyele sahiptir. Haziran, Temmuz ve Mayıs ayları en yüksek güneş 1şınımı değerlerine ulaşıldığı aylar olurken, bu değerler Aralık ve Ocak aylarında düşmektedir. Ürgüp bölgesinde ise yıl bazında $1580 \mathrm{kWh} / \mathrm{m}^{2}$ 'lik güneş 1 şınımı değerine ulaşılabilmektedir.

Ülke ortalamasının oldukça üzerinde güneşlenme değerlerine sahip olan Ürgüp'te önemli GES yatırımlarının gelme potansiyeli oldukça yüksektir. Ürgüp yaz ve kış aylarında olmak üzere günlük 3,61 ile 12, 14 saat arasından değişen güneşlenme sürelerine sahiptir [1].

Tükettiği elektriği şebekeden temin eden otellerde enerji maliyetlerinin artması turizm işletmelerini alternatif enerji kaynaklarına yönlendirmektedir. Karlılıklarını artırmak ve giderlerini azaltmak isteyen şirketler, oteller de enerji tasarrufunun yanı sıra giderlerini düşürmek için hali hazırdaki ölü alanlarını güneş enerjisinden faydalanmak için PV paneller kullanarak değerlendirme yoluna gitmektedirler.

Bu doğrultuda Ürgüp'te turizm sektöründe yer alan konaklama işletmelerinin faaliyetlerini daha ekonomik olarak sürdürebilmeleri için güneş enerjisine yönelerek yatırım yapmalarını avantajlı kılmaktadır. Çünkü enerjide sürdürülebilirliğin güneş enerjisi ile sağlanması halinde turizm hizmet maliyetlerinin düşmesi ve ekonomik bir ortamın sağlanması mümkün olacaktır.

$\mathrm{Bu}$ mana da bölgede faaliyet gösteren konaklama otelleri modern güneş enerjisi sistemleriyle kendi enerjilerini üretip işletmelerinin enerji maliyetlerini düşürmek imkanına sahip bulunmaktadırlar.

Güneş enerjisinin kullanımı konusunda gerçekleştirilecek planlamalarda güneş 1şınımı hesaplamaları büyük önem taşımaktadır. Güneş ışınımı hesaplamaları kurulacak güneş enerjisi sistemlerinin üreteceği elektrik miktarlarının belirlenmesini sağlamaktadır.

$\mathrm{Bu}$ manada literatürde çok sayıda çalışma bulunmaktadir.

Külcü [2], Isparta İli'nde atmosfer dışına gelen güneş 1şınımı ile yeryüzüne gelen 1şınımı Angstrom-Prescott tabanlı modelleri ile tahmin etmişlerdir.

Taşkın ve Korucu [3], bir çalışmalarında Kahramanmaraş İli güneş enerjisi potansiyeli ve kullanım olanaklarını araştırmışlar ve bölgenin y1llık toplam 2918 saat güneşlenme süresine ve $1608 \mathrm{kWh} / \mathrm{m}^{2}$ 1şınım şiddetine sahip olduğu belirlenmişlerdir.

Bakırc1 [4], güneşlenme süresine bağlı olarak farklı tipteki Angström-tip eşitliklerin yardımıyla Erzurum'da aylık ortalama günlük global (toplam) güneş 1şınımının tahmini için kullanılabilirliğini araştırmıştır. Üstelik Erzurum'da aylık ortalama günlük global güneş 1şınımı hesabı için, üçüncü dereceden bir eşitlik geliştirmiştir. 
Kallioğlu ve arkadaşları [5], Adıyaman İli için yatay düzleme gelen toplam güneş 1şınımını araştırmışlardır. Yapılan bu araştırma sonucunda, güneş 1şınımı tahmininde kullanılacak polinom model ile sayısal modellemenin gerçeğe yakın kararlı sonuçlar verdiğini ifade etmişlerdir.

Karaca ve Uçar [6], Burdur İli için bir konutun ortalama günlük enerji ihtiyacının karşılanabilmesi için 4 farklı PV sistemi değerlendirilmiştir. PV panellerin $10^{\circ}-30^{\circ}$ arasında eğim ile çatıya konumlandırılmasını önermişlerdir.

PV sistemi ve güneş 1şınımı ile ilgili araştırmalar genellikle Angström-tip eşitlikler veya yapay sinir ağları kullanılarak gerçekleştirilmektedir [7].

Ancak meteorolojik veriler gibi bazı veri tiplerinin istatistiksel olarak belirli kurallara göre dağılım gösterdiği bilinmektedir [8].

İstatistiksel çözümlemeler ise belirli bir olasılık dağılımına dayandırıldığında çözümlemede kullanılan değişkenlerin bu olasılık dağılımına uyması gerekir.

$\mathrm{Bu}$ çalışmada güneş 1şınımı verilerinin bir olasılık dağılımına uyduğu varsayımıyla Weibull ve Lognormal dağılımları ile modelleme yapılmıştır.

$\mathrm{Bu}$ dağılımlar genellikle dünyanın birçok bölgesinin rüzgâr dağılımını temsil etmek için kullanılan dağılımlardır

Ancak güneşlenme süresi, sıcaklık ve bulutluluk gibi parametreler ile global güneş 1şınımı arasındaki ilişkiye dayanan Angström-tip istatiksel modeller dikkate alındığında istatistiksel dağılımların da değerlendirilmesi mümkündür[9].

Diğer yandan güneş enerjisi, güneş hücresinin yapısına bağlı olarak kullanılan teknolojiye göre $\% 10$ ile $\% 25$ arasında bir verimle elektrik enerjisine çevrilebilmektedir [10].

Güneş paneli verimliliği, bir güneş panelinin güneş ışığını ne kadar iyi yakaladığını ve bunu elektrik enerjisine dönüştürdüğünün bir göstergesidir. Aynı koşullar altında, yüksek verimli güneş paneli aynı boyuttaki daha düşük verimlilikte bir panelden daha fazla elektrik üretebilir. $\mathrm{Bu}$ nedenle güneş ışınımı araştırmalarında güneş panellerinin verimi de dikkate alınmalıdır. Konuya ilgi duyan yatırımcılar ve araştırmacılar açısından mevcut istatistiksel programlar ile daha düşük maliyet ve daha az ölçüm verisi kullanılarak PV potansiyeli belirleme konusunda farklı yöntemlerin bulunması önemlidir.

Çalışma ile literatürde genellikle rüzgar enerjisi tahmininde kullanılan olasılık dağılımlarının bu çalışmayla birlikte güneş enerjisi değerlendirmelerinde farklı bir bakış açısı olarak kullanılabilirliğini ortaya koymak hedeflenmiştir.

$\mathrm{Bu}$ çalışmada Ürgüp bölgesinde Weibull ve Lognormal dağılımları ile modellenen eğik düzleme düşen güneş 1şınımının sabit panel verimi ve eğimi şartlarında elde edilebilecek GaAs Tip PV enerji üretim potansiyeli araştırılmıştır.

\section{MATERYAL VE METOT}

\subsection{Materyal}

Ürgüp, Nevşehir İli'ne bağlı ve il merkezine $20 \mathrm{~km}$ uzaklikta yer alan (boylam: 34.912182, enlem: 38.631169) bir ilçedir. Her yıl yerli yabancı pek çok turist ziyaret edilen Ürgüp'te yaz aylarında havanın oldukça sıcak geçmesi yerli ve yabancı turist sayısının da zirve noktaya ulaşmasının etkisi ile elektrik talebi artmaktadır. Elektrik tüketiminin büyük bir kısmının turistik tesislerde gerçekleşmesi ve elektrik maliyetinin otellerin gider kalemleri arasında üst sıralara yükselmesi bölgede alternatif enerji kaynaklarına olan ilgiyi arttırmaktadır [11].

$\mathrm{Bu}$ çalışmada bölgenin güneş enerjisi potansiyelinin belirlenmesi amaciyla Meteoroloji Genel Müdürlüğü tarafından 2007-2010 yılları arasında kayıt altına alınan meteoroloji ve güneş verileri kullanılmıştır [12]. Ölçümlerin yapıldığ1 bölgeye ait harita Şekil 1'de görülmektedir. 


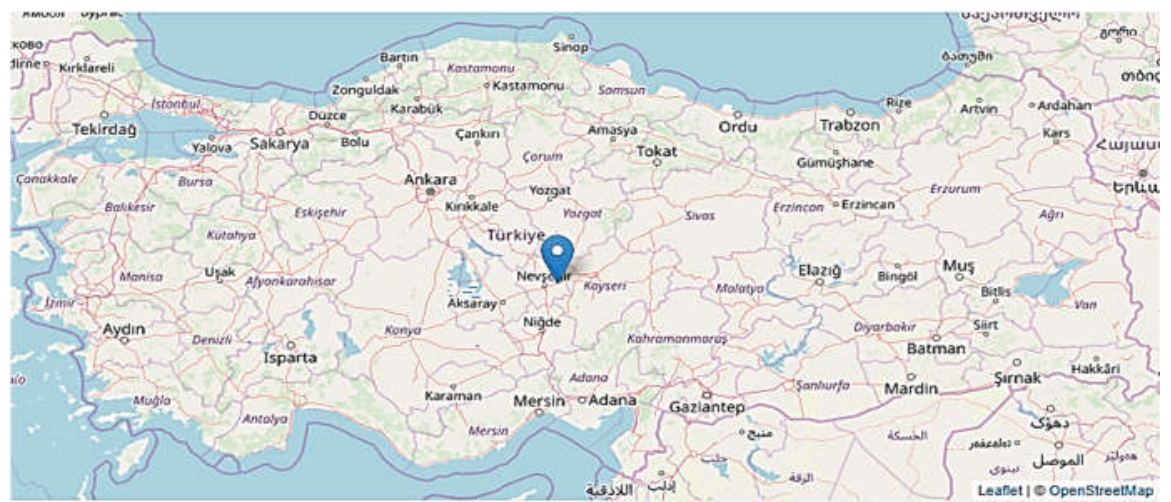

Şekil 1. Ölçümlerin yapıldığg bölgeye ait harita (Openstreetmap, 2019)

\subsection{Güneş Enerjisi}

Üretilen PV gücünü hesaplamak için toplam küresel radyasyon gereklidir. Solar PV panellerinin potansiyelin belirlenmesi açısından panel güç çıkışı $\left(P_{P V}\right)$ ampirik olarak Eşitlik 1 kullanılarak hesaplanabilir [13].

$\mathrm{P}_{\mathrm{PV}}=\mathrm{H}_{\mathrm{T}} \eta_{\mathrm{PV}} \mathrm{A}_{\mathrm{PV}}$

burada $\mathrm{H}_{\mathrm{T}}$, ortalama güneş 1 şınımı $\left(\mathrm{Mj} / \mathrm{m}^{2}\right), P_{P V}$ toplam elektrik gücü, $A_{P V} \mathrm{PV}$ panel alanı ve $\eta_{P V}$ ise $\% 18$ olarak alınan PV panellerin elektriksel verimliliğidir. Eşitlikte PV'ler için belirlenen enerji üretim değerleri eğik düzleme düşen aylık ortalama günlük radyasyon değerleri ile hesaplanmaktadir.

PV panellerde hem fotoelektrik dönüşüm verimliliği hem de güç dönüşüm verimliliğinin kademeli olarak düşmesine rağmen, bu parametrelerin varyasyonlarının sistemin kullanım ömrü boyunca çok az olduğu ve bu nedenle PV potansiyeli hesaplamaları açısından göz ardı edilebileceği dikkat çekmektedir.

PV sisteminin güç çıkışı yalnızca sistem yapılandırmasıyla ilgili değil aynı zamanda birçok hava koşulundan da etkilenir. $\mathrm{Bu}$ nedenle mevcut PV güç tahmin yöntemlerinin çoğu meteorolojik koşulları girdi değişkenleri olarak alır. Böylece, sistemin çıktısının PV güç değerleri çok değişkenli, zamana göre değişen dinamik bir sistem olarak modellenebilir.
Eğik bir yüzey üzerinde meydana gelen güneș ışınımı dikkate alındığında, eğimli bir PV paneli için $H_{T}$, meydana gelen toplam radyasyon $\left(\mathrm{Mj} / \mathrm{m}^{2}\right)$ olup, direkt, difüz ve yansıyan bileşenlerden oluşur [14] (Eşitlik 2).

$$
\mathrm{H}_{\mathrm{T}}=\mathrm{H}\left(1-\frac{\mathrm{H}_{\mathrm{D}}}{\mathrm{H}}\right) \overline{\mathrm{R}}_{\mathrm{b}}+\mathrm{H}_{\mathrm{d}}\left(\frac{1+\cos \beta}{2}\right)+\mathrm{H} \rho\left(\frac{1-\cos \beta}{2}\right)
$$

Burada $\bar{R}_{b}$ eğik yüzeye düșen günlük direkt 1şınımın $\left(\mathrm{H}_{\mathrm{bT}}\right)$ yatay yüzeye düşen günlük direkt 1şıma $(\mathrm{H} b)$ oranı olarak tanımlanabilir [15] (Eşitlik 3).

$$
\overline{\mathrm{R}}_{\mathrm{b}}=\frac{\mathrm{H}_{\mathrm{bT}}}{\mathrm{H}_{\mathrm{b}}}
$$

Kuzey yarımkürede güneye dönük yüzey için; (Eşitlik 4).

$\overline{\mathrm{R}}_{\mathrm{b}}=\frac{\cos (\phi-\beta) \cos \delta \sin \omega_{\mathrm{s}}^{\prime}+\left(\frac{\pi}{180}\right) \omega_{\mathrm{s}}^{\prime} \sin (\phi-\beta) \sin \delta}{\cos \phi \cos \delta \sin \omega_{\mathrm{s}}+\left(\frac{\pi}{180}\right) \omega_{\mathrm{s}} \sin \phi \sin \delta}$

Burada $\omega_{\mathrm{s}}^{\prime}$ hesaplama yapılan ayın ortalama gününde eğik düzlem için güneş ışınlarının eğik yüzey üzerine ilk düşüş saat açısıdır. $\beta, \phi$, ve $\delta$ yüzeyin eğim açısını ( ${ }^{\circ}$ derece), enlem açısını $\left({ }^{\circ}\right.$ derece) ve deklinasyon açısını $\left({ }^{\circ}\right.$ derece) ifade etmektedir (Eşitlik 5).

$\delta=23,45 \operatorname{Sin}\left(360\left(\frac{284+\mathrm{n}}{365}\right)\right.$

$\omega_{\mathrm{s}}$ ve $\omega_{\mathrm{s}}^{\prime}$ ise Eşitlik 6 ve 7'de verildiği şekilde hesaplanabilir.

$\omega_{\mathrm{s}}=\cos ^{-1}(-\tan \phi \tan \delta)$ 
$\omega_{\mathrm{s}}^{\prime}=\min \left[\begin{array}{c}\cos ^{-1}(-\tan \phi \tan \delta) \\ \cos ^{-1}(-\tan (\phi-\beta) \tan \delta)\end{array}\right]$

indeksi $\left(\mathrm{K}_{\mathrm{T}}\right)^{\prime}$ 'ne bağlı $\mathrm{H}_{\mathrm{d}} / \mathrm{H}$ oranı ise TübitakM.A.M. tarafından yapılan ölçümler neticesinde elde edilen verilere bağlı olarak regresyonel olarak aşağıda verildiği şekilde ifade edilebilir [16] (Eşitlik 8).

$\frac{\mathrm{H}_{\mathrm{d}}}{\mathrm{H}}=0,703-0,414 \mathrm{~K}_{\mathrm{T}}-0,428 \mathrm{~K}_{\mathrm{T}}^{2}$

Burada $K_{T}$ yatay düzleme gelen günlük toplam güneş 1şınımı $(\mathrm{H})$ 'ın atmosfer dişına düşen günlük toplam güneş 1 şınımı $\left(\mathrm{H}_{0}\right)^{\prime}$ na $\left(\mathrm{Mj} / \mathrm{m}^{2}\right)$ oranıdır.

\subsection{Olasılık Yoğunluk Fonksiyonları}

$\mathrm{Bu}$ çalışmada PV panel güç üretimini değerlendirmek için önce sahadaki $\mathrm{H}_{\mathrm{T}}$ modellenmiştir. Bunu yapmak için, $\mathrm{H}_{\mathrm{T}}$ olasılığ 1 , Weibull olasılık dağılım fonksiyonu (OYF) ile temsil edilmiştir. $\mathrm{H}_{\mathrm{T}}$ açısından Weibull OYF aşağıdaki şekilde verilebilir [17] (Eşitlik 9).

$\mathrm{f}\left(\mathrm{H}_{\mathrm{T}}\right)_{\mathrm{W}}=\frac{\mathrm{k}}{\mathrm{c}}\left(\frac{\mathrm{H}_{\mathrm{T}}}{\mathrm{c}}\right)^{\mathrm{k}-1} \exp \left[-\left(\frac{\mathrm{H}_{\mathrm{T}}}{\mathrm{c}}\right)^{\mathrm{k}}\right]$

Burada $k$ ve $c$ sırasıyla sırasıyla, şekil (shape) ve ölçek (scale) parametreleridir.

İki Weibull parametresini, k ve c'yi belirlemek için Maksimum Likelihood ve en küçük kareler metodu gibi birçok farklı yöntem vardır. $\mathrm{Bu}$ çalışmada parametreler Maksimum Likelihood metodu (MLM) kullanılarak türetilmiş ve en iyi k ve c parametreleri, her ay için belirlenmiştir.

Sahadaki $\mathrm{H}_{\mathrm{T}}$ olasılığı ayrıca Lognormal olasılık dağılım fonksiyonu (OYF) ile temsil edilmiştir.

$\mathrm{H}_{\mathrm{T}}$ 'ye ilişkin $\ln \mathrm{H}_{\mathrm{T}}$ olasılık dağılımı normal ise, $\mathrm{H}_{\mathrm{T}}$ 'nin olasılık dağılımı, logaritmik normal dağılım ya da kısaca lognormal dağılım terimiyle adlandırılabilir. $\mathrm{Bu}$ durumda OYF şöyledir; (Eşitlik 10).

$\mathrm{f}\left(\mathrm{H}_{\mathrm{T}}\right)_{\mathrm{L}}=\frac{1}{\sigma \mathrm{H}_{\mathrm{T}} \sqrt{2 \pi}} \exp \left[-\frac{1}{2}\left(\frac{\ln \mathrm{H}_{\mathrm{T}}-\mu}{\zeta}\right)^{2}\right]$
Burada $\sigma$ v $\mu$ sırasıyla ölçek ve lokasyon parametreleridir.

\subsection{Hata Değerlendirme Kriterleri}

İstatistiksel veri olarak, ortalama hata kareleri kökü (RMSE) kısa dönem ölçülen ve tahmin edilen model performanslarının kıyaslanması açısından önemli olup Eşitlik 10 ile hesaplanabilir. RMSE her zaman pozitif değerli olup ideal değeri sıfıra en yakın sonuçtur (Eşitlik 11).

$\mathrm{RMSE}=\sqrt{\frac{1}{\mathrm{n}} \sum_{\mathrm{i}=1}^{\mathrm{n}}\left(\mathrm{m}_{\mathrm{i}}-\mathrm{c}_{\mathrm{i}}\right)^{2}}$

Belirlilik katsayısı $\left(\mathrm{R}^{2}\right)$ bir değişkenin diğerine hangi oranda bağlı olduğu diğer bir deyişle bağımlı ve bağımsız değişken arasındaki ilişkinin yönü hakkında bir göstergedir [18]. Hesaplanan ve ölçülen değerler arasındaki doğrusal ilişkiyi yorumlayabilmek için kullanılır. $\mathrm{R}^{2}$ değeri 0 ile 1 arasındadır. İdeali 1'e en yakın değerdir (Eşitlik 12).

$\mathrm{R}^{2}=\frac{\sum_{\mathrm{i}=1}^{\mathrm{n}}\left(\mathrm{c}_{\mathrm{i}}-\mathrm{c}_{\mathrm{a}}\right)\left(\mathrm{m}_{\mathrm{i}}-\mathrm{m}_{\mathrm{a}}\right)}{\sum_{\mathrm{i}=1}^{\mathrm{n}}\left(\mathrm{c}_{\mathrm{i}}-\mathrm{c}_{\mathrm{a}}\right)^{2} \sum_{\mathrm{i}=1}^{\mathrm{n}}\left(\mathrm{m}_{\mathrm{i}}-\mathrm{m}_{\mathrm{a}}\right)^{2}}$

Burada, $c_{i}$ hesaplanan değeri gösterirken, $m_{i}$ ölçülen değeri simgelerken, $c_{a}$ ve $m_{a}$ ise hesaplanan ve ölçülen değerlerin ortalamasıdır.

\section{BULGULAR VE TARTIŞMA}

Fotovoltaik sistem uygulamalarında eğik düzleme düşen aylık ortalama günlük güneş 1şınımı miktarlarının hesaplanabilmesi için eğik düzleme düşen aylık ortalama günlük toplam ışınımın $\left(\mathrm{H}_{\mathrm{T}}\right)$, bilinmesi gereklidir. $\mathrm{Bu}$ amaçla ölçüm verilerinde yer alan yatay yüzeye düşen günlük direkt 1 şıma değerleri ve Eşitlik 2-8 yardımıyla $35^{\circ}$ eğime sahip PV paneli için $H_{T} \quad\left(\mathrm{Mj} / \mathrm{m}^{2}\right)$ değerleri hesaplanmıştır. Aylık bazda günlük ortalamalar dikkate alındığında $H_{T}\left(\mathrm{Mj} / \mathrm{m}^{2}\right)$ için ortalama, standart sapma (StSap) ve varyans değerleri $18,371,2,982$ ve $8,895 \quad\left(\mathrm{Mj} / \mathrm{m}^{2}\right)$ olarak hesaplanmıştır. Bununla birlikte minimum ve maksimum değerleri ise 13,513 ve $22,519\left(\mathrm{Mj} / \mathrm{m}^{2}\right)$ olarak hesaplanmıştır. 
Elde edilen $H_{T}\left(\mathrm{Mj} / \mathrm{m}^{2}\right)$ değerleri Eşitlik 9 ve 10 ile verilen Weibull ve Lognormal dağılmıları ile modellenmiştir. Modellere ait parametreler ve StSap değerleri Çizelge 1'de verilmektedir.

Çizelge 1'de görüldüğü gibi Weibull OYF'e ait en büyük $\mathrm{k}$ ve c değerleri 24,2359 ve 23,1328 $\left(\mathrm{Mj} / \mathrm{m}^{2}\right)$ (Eylül), en küçük $\mathrm{k}$ ve c değerleri ise
2,3925 ve $15,1728\left(\mathrm{Mj} / \mathrm{m}^{2}\right) \quad$ (Aralık) olarak belirlenmiştir.

Lognormal OYF'e $\mu$ değerleri yıl boyunca 2,4742 ile 3,0619 arasında değişirken $\sigma$ değerleri 0,0945 ile $0,5355\left(\mathrm{Mj} / \mathrm{m}^{2}\right)$ arasında değişmektedir. StSap değerleri ise yaz aylarında düşerken mevsim geçişleriyle birlikte artış eğilimi göstermektedir.

Çizelge 1. Weibullve Lognormal OYF parametreleri

\begin{tabular}{|c|c|c|c|c|c|c|}
\hline \multirow{2}{*}{ Ay } & \multicolumn{2}{|c|}{ Weibull OYF parametreleri } & \multicolumn{3}{c|}{ Lognormal OYF parametreleri } \\
\cline { 2 - 7 } & $\mathrm{k}$ & $\mathrm{c}$ & StSap & $\mu$ & $\sigma$ & StSap \\
\hline 1 & 3,7780 & 17,0576 & 4,5525 & 2,6656 & 0,3798 & 6,0861 \\
\hline 2 & 4,0492 & 19,3128 & 4,8603 & 2,8078 & 0,3307 & 5,9502 \\
\hline 3 & 3,6384 & 19,7018 & 5,4285 & 2,8133 & 0,3634 & 6,6883 \\
\hline 4 & 3,9982 & 21,3723 & 5,4368 & 2,9076 & 0,3433 & 6,8707 \\
\hline 5 & 6,7469 & 20,9798 & 3,4055 & 2,9477 & 0,2132 & 4,2049 \\
\hline 6 & 16,2814 & 21,6736 & 1,5860 & 3,0327 & 0,1058 & 2,2142 \\
\hline 7 & 16,1217 & 22,2473 & 1,6430 & 3,0619 & 0,0945 & 2,0323 \\
\hline 8 & 15,4098 & 22,0534 & 1,6986 & 3,0473 & 0,1353 & 2,8889 \\
\hline 9 & 24,2359 & 23,1328 & 1,1634 & 3,1071 & 0,1320 & 2,9893 \\
\hline 10 & 5,1212 & 19,3428 & 3,9854 & 2,8403 & 0,2788 & 5,0598 \\
\hline 11 & 2,4321 & 15,7186 & 6,1131 & 2,5043 & 0,5355 & 8,1372 \\
\hline 12 & 2,3925 & 15,1728 & 5,9861 & 2,4742 & 0,5107 & 7,3838 \\
\hline
\end{tabular}

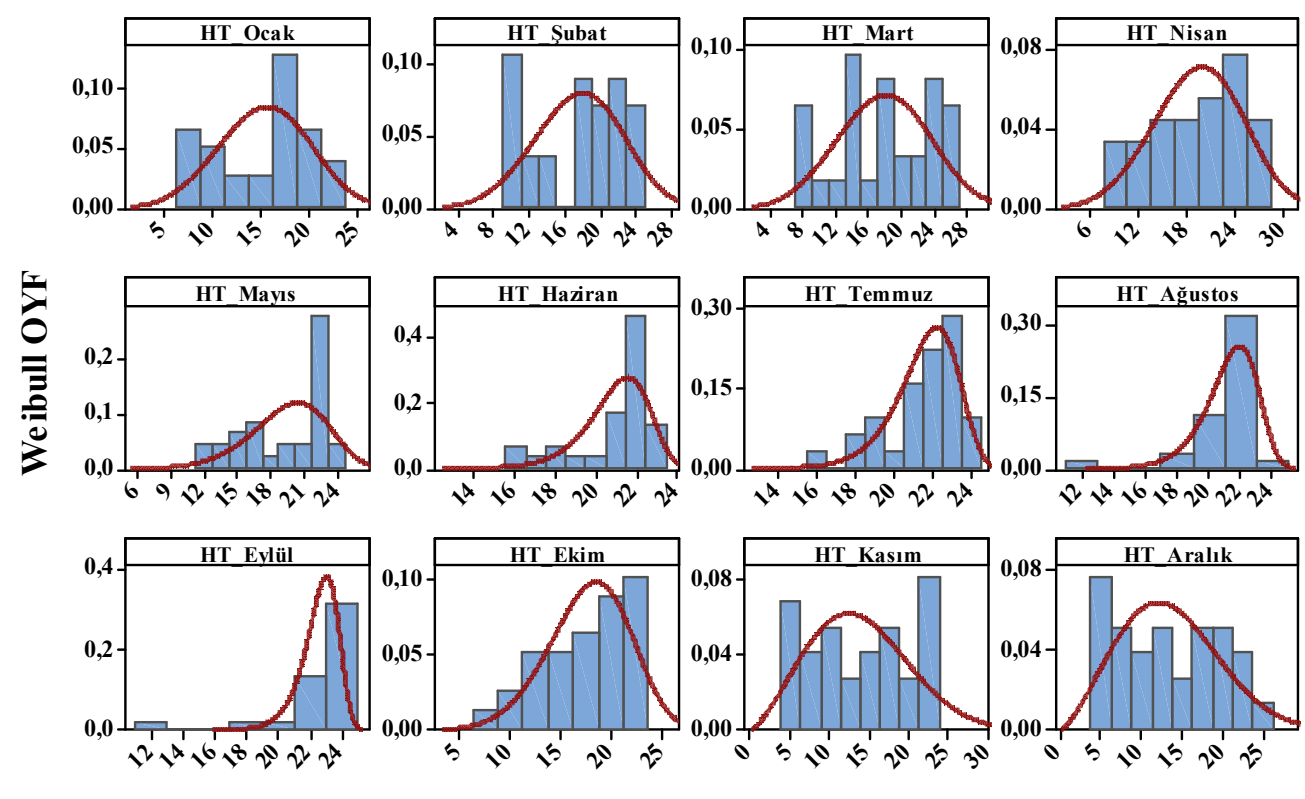

Eğik yüzeye düsşen güneş ışınımı $(\mathrm{Mj})$

Şekil 2. $\mathrm{H}_{\mathrm{T}}$ dağılım olasılığının Weibull OYF ile modellenmesi 


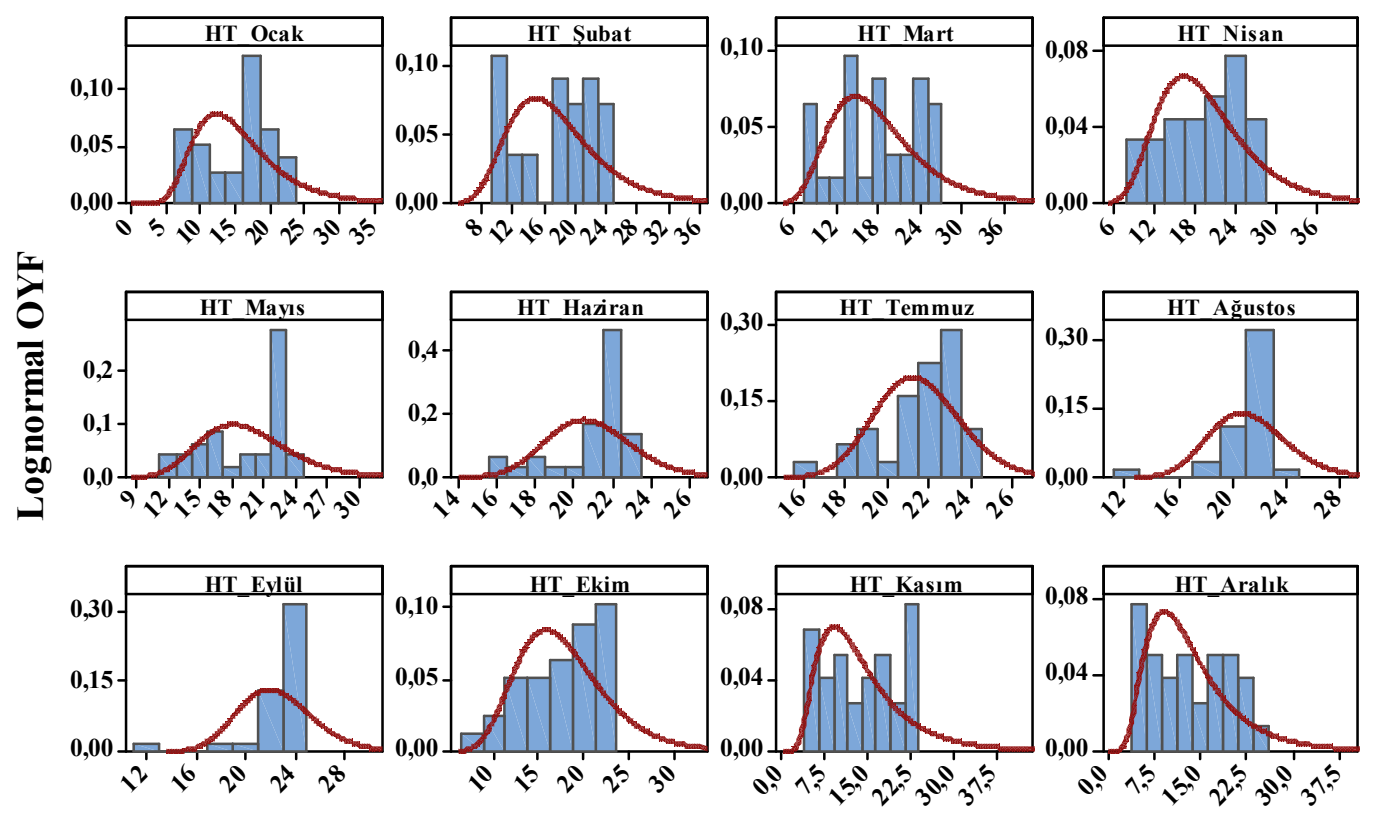

Eğik yüzeye düşen güneş ışınımı (Mj)

Şekil 3. $H_{T}$ dağılım olasılığının Lognormal OYF ile modellenmesi

Şekil 2'de $H_{T}\left(\mathrm{Mj} / \mathrm{m}^{2}\right)$ dağılım sıklığının Weibull OYF ile modellenmesi görülmektedir. Burada Weibull OYF, $H_{T} \quad\left(\mathrm{Mj} / \mathrm{m}^{2}\right)$ 'nin herhangi bir şiddette yüzeye düşme değerinin olasılığını gösteren fonksiyondur. c ve $\mathrm{k}$ değerleri artıkça olasılık eğrisinin sağa çarpık hale geldiği ve olasılığın 0 dan uzaklaştığı yani yüksek $H_{T}$ $\left(\mathrm{Mj} / \mathrm{m}^{2}\right)$ sıklığını daha iyi modellediği görülmektedir.

Şekil 3'de $H_{T}\left(\mathrm{Mj} / \mathrm{m}^{2}\right)$ dağılımının Lognormal OYF ile modellenmesi görülmektedir. Burada Lognormal OYF, $H_{T}\left(\mathrm{Mj} / \mathrm{m}^{2}\right)$ 'nin herhangi bir şiddette yüzeye düşme değerinin olasılığını gösteren fonksiyondur. $\mu$ değerlerinin azalmasıyla olasılık eğrisinin sola çarpık hale geldiği ve 0'a yaklaştığı yani düşük $H_{T}\left(\mathrm{Mj} / \mathrm{m}^{2}\right)$ sıklığını daha iyi modellediği görülmektedir. Yaz aylarında ise basıklığın azalarak normal dağılıma yaklaştığı görülmektedir.

Weibull ve Lognormal OYF ile gerçekleştirilen $\mathrm{H}_{\mathrm{T}}$ tahmin değerleri Çizelge 2'de verilmektedir.
Çizelge 2. Weibull ve Lognormal OYF $\mathrm{H}_{\mathrm{T}}$ tahmini

\begin{tabular}{|c|c|c|c|}
\hline Ay & $\mathrm{H}_{\mathrm{T}}$ & $\mathrm{H}_{\mathrm{T} \text { Wei }}$ & $\mathrm{H}_{\mathrm{T} \text { Log }}$ \\
\hline 1 & 15,3323 & 15,4114 & 15,4515 \\
\hline 2 & 17,4327 & 17,5173 & 17,5041 \\
\hline 3 & 17,6986 & 17,7636 & 17,8021 \\
\hline 4 & 19,3081 & 19,3714 & 19,4248 \\
\hline 5 & 19,4728 & 19,5875 & 19,4999 \\
\hline 6 & 20,8638 & 20,9818 & 20,8696 \\
\hline 7 & 21,4605 & 21,5309 & 21,4644 \\
\hline 8 & 21,2265 & 21,3141 & 21,2516 \\
\hline 9 & 22,5191 & 22,6194 & 22,5510 \\
\hline 10 & 17,7267 & 17,7845 & 17,7992 \\
\hline 11 & 13,8937 & 13,9379 & 14,1214 \\
\hline 12 & 13,5130 & 13,4496 & 13,5259 \\
\hline Hata & $\mathrm{RMSE}$ & 0,0352 & 0,0568 \\
\cline { 2 - 4 } Uyum & $\mathrm{R}^{2}$ & 0,9998 & 0,9994 \\
\hline
\end{tabular}

Weibull OYF ile gerçekleştirilen $\mathrm{H}_{\mathrm{T}}$ tahmin değerleri 13,4496 ile 22,6194 $\left(\mathrm{Mj} / \mathrm{m}^{2}\right)$ değerleri arasında değişisiken Lognormal OYF ile gerçekleştirilen $\mathrm{H}_{\mathrm{T}}$ tahmin değerlerinin 13,5259 ile $22,5510\left(\mathrm{Mj} / \mathrm{m}^{2}\right)$ değerleri arasında değiştiği Çizelge 2'de görülmektedir. Model değerlendirme kriteri olarak kullanılan RMSE ve $\mathrm{R}^{2}$ değerleri 
incelendiğinde ise Weibull OYF ile gerçekleştirilen $\mathrm{H}_{\mathrm{T}}$ tahmin değerleri gözlem değerleri ile daha uyumlu olduğu görülmektedir. Weibull OYF ile 0,9998 $\mathrm{R}^{2}$ değerine ulaşılırken hata değeri olarak RMSE için 0,0352 değerinin yakalandığı görülmektedir. Bu manada hesaplanan parametre değerlerine göre çizilen Weibull sıklık eğrisinin ve ortalama $\mathrm{H}_{\mathrm{T}}$ tahmin değerlerinin gözlem verilerini daha iyi temsil ettiği görülmektedir.

Galyum arsenit (GaAs) fotovoltaik uygulamalar için en yaygın kullanılan yarı iletken bileşiklerden biridir. GaAs-GaAs Solar Hücre Teknolojisi yüksek elektron hareketliliği sayesinde \%30 verimlilik oranına ulaşmaktadır. Amerika'da faaliyet gösteren Ulusal Yenilenebilir Enerji Laboratuarı (NREL) tarafından dünyada en yüksek verime sahip PV modülleri arasında gösterilmektedir. Kristalin silikon PV sistemlere göre 1şı̆̆a duyarlılığı daha yüksek olan GaAs tip PV modülleri $250{ }^{\circ} \mathrm{C}$ 'ye ulaşan sıcaklıklara dayanabilmektedir. $\mathrm{Bu}$ nedenle çalışma esnasında PV potansiyeli hesaplanırken GaAs tip PV modülleri dikkate alınmıştır. Bununla birlikte, endüstriyel olarak üretilen güneş modülleri, standart test koşulları altında \%18 ila \%22 arasında değişen verim elde etmektedir. $\mathrm{Bu}$ nedenle hesaplamalarda \%18 verimlilik esas alınmıştır [19].

Meteorolojiden elde edilen verilerle hesaplanan $\mathrm{H}_{\mathrm{T}}$ değerleri ve Weibull ve Lognormal OYF ile gerçekleştirilen $\mathrm{H}_{\mathrm{T}}$ tahmin değerlerine bağlı olarak Eşitlik 1 yardımıyla elde edilen aylık PV enerji üretim potansiyeli değerleri $6,8 \mathrm{~m}^{2}$ panel alanı dikkate alındığında Şekil 4'de görülmektedir. Bölgenin Ekim ayına kadar düzenli olarak artan üretim potansiyeline sahip olduğu değerlendirilmektedir. Gözlemlerde elde edilen $\mathrm{P}_{\mathrm{PV}}$ değerleri gün bazında aylık ortalama 138035,265 ve $230032,977 \mathrm{~W}$ arasında değişirken Weibull ve Lognormal ile $\mathrm{P}_{\mathrm{PV}}$ tahmin değerleri 137387,7 ile 231057,2 ve 138167,1 ile 230358,5 W arasında değişmektedir. Gözlemlerde elde edilen ve Weibull ve Lognormal $\mathrm{H}_{\mathrm{T}}$ tahmin değerlerine bağlı olarak hesaplanan yıllık bazda enerji üretim potansiyeli değerleri 2251,87, 2260,27 ve $2260,23 \mathrm{~kW}$ olarak hesaplanmıştır.

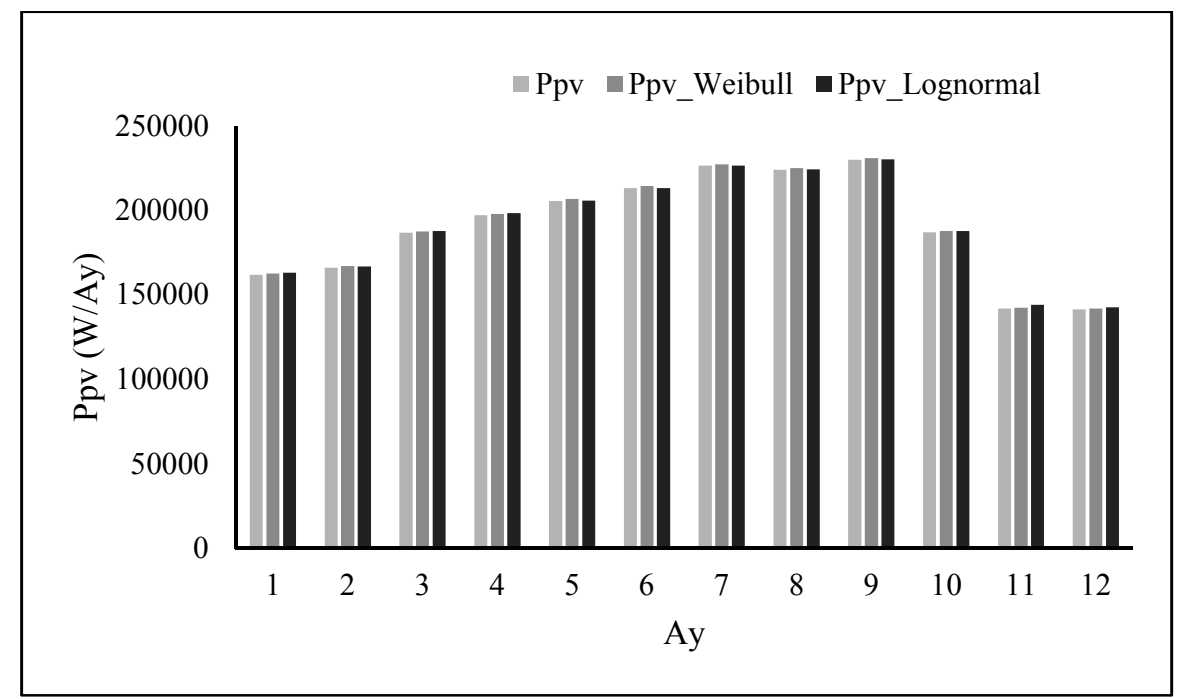

Şekil 4. Weibull ve Lognormal OYF ile $\mathrm{P}_{\mathrm{PV}}$ tahmini

Önceki çalışmalar [20-24] ve değerlendirmeler ışı̆̆ında yenilenebilir enerji kaynaklarından enerji elde ediniminin özellikle güneş enerjisi kaynaklı üretim tekniklerinin önemini koruduğu açıktır.
Etier ve arkadaşları [25], $10 \mathrm{~kW}$ PV sistemin tasarımını ve simülasyonunu araştırmışlar. 50-110$300 \mathrm{~W}$ güce sahip paneller ile yapılan çalışmalarda yıllık $17515 \mathrm{~kW}$ üretim değerlerini ulaşıldığııı 
ifade etmişlerdir. Rai ve arkadaşları [26], Hindistan'da, $100 \mathrm{~kW}$ PV sistem üzerinde yaptıkları çalışmalarda yıllık $156120 \mathrm{~kW}$ üretim değerlerine ulaşılabileceğini değerlendirmişlerdir. Kumar ve Sudhakar [27], Ramagundam'da kurulu 10 MW'lı şebekeye bağlı güneş fotovoltaik enerji santralinin performans çalışması yıllık olarak değerlendirmişler ve yıllık bazda 16047 MW üretim değerlerine ulaşılabileceğini bildirmişlerdir. $\mathrm{Bu}$ araştırmalar 1 şı̆̆ında çalışmanın literatürle ile uyumlu değerlendirilmektedir.

\section{SONUÇLAR}

Bu çalışma ile temel düşünce olarak rüzgar enerjisi tahmininde kullanılan olasılık dağılımlarının güneş enerjisi değerlendirmelerinde farklı bir yaklaşım olarak kullanılabilirliği araştırılmıştır.

Zira PV potansiyeli belirleme konusunda olasılık dağılım fonksiyonları ile düşük maliyetle ve daha az ölçüm verisi kullanarak önemli sonuçlara ulaşmak mümkündür.

$\mathrm{Bu}$ amaçla çalışmada, Ürgüp bölgesinde eğik düzleme düşen aylık ortalama günlük toplam ışınımın (HT) yoğunluğu ve dağılımı parametrelerinin istatistiksel analizi, 2007-2010 yılları arasında ölçülen güneş verileri kullanılarak gerçekleştirilmiştir. Modelleme için Weibull ve Lognormal olasılık dağılımları kullanılmıştır. Nihayetinde ise aylık PV enerji üretim potansiyeli değerleri ve modelleme işleminin başarısını değerlendirmek için RMSE ve $\mathrm{R}^{2}$ değerleri hesaplanmıştır. Elde edilen sonuçlar kısaca özetlemek gerekirse; aylık bazda günlük ortalamalar dikkate alındığında $H_{T} \mathrm{Mj} / \mathrm{m}^{2}$ için ortalama değer $18,371 \quad \mathrm{Mj} / \mathrm{m}^{2}$ olarak hesaplanmıştır. Bununla birlikte minimum maksimum $H_{T} \mathrm{Mj} / \mathrm{m}^{2}$ değerleri ise 13,5130 ve 22,5191 Mj/m² olarak hesaplanmıştır.

Weibull dağılımına ait en büyük $\mathrm{k}$ ve c değerleri 24,2359 ve $23,1328 \mathrm{Mj} / \mathrm{m}^{2}$ Eylül ayı için hesaplanmıştır

Lognormal dağılımına ait $\sigma$ değerleri 0,0945 ile $0,5355 \mathrm{Mj} / \mathrm{m}^{2}$ arasında değişmektedir.
Weibull dağılımı ile model başarısında $0,9998\left(\mathrm{R}^{2}\right)$ ve 0,0352 (RMSE) değerlerine ulaşılmıştır.

Gözlemlerde elde edilen $\mathrm{H}_{\mathrm{T}}$ değerleri, ay bazında günlük ortalama 13,5130 ve $22,5191 \mathrm{Mj} / \mathrm{m}^{2}$ arasında değişirken yıllık bazda PV enerji üretim potansiyeli değeri 2251,87 kW seviyesine ulaşmaktadır.

Sonuç olarak Weibull sıklık eğrisinin ve hesaplanan ortalama $\mathrm{H}_{\mathrm{T}}$ tahmin değerlerinin, gözlem verilerini daha iyi temsil ettiği ve y1l bazında PV enerji üretim potansiyelini modelleyebilme esnekliğine sahip olduğu değerlendirilmektedir.

\section{TEŞEKKÜR}

Yazar veri paylaşımından dolayı Türkiye Meteoroloji Genel Müdürlüğüne teşekkür eder.

\section{KAYNAKLAR}

1. Canka Kilıç, F., 2015. Güneş Enerjisi, Türkiye'deki Son Durumu ve Üretim Teknolojileri, Engineer \& The Machinery Magazine, 56(61), 28-40

2. Külcü, R., 2015. Isparta'da Yeryüzüne Ulaşan Güneş Işınımının Modellenmesi, Sdü Ziraat Fakültesi Dergisi, 10(1), 19-26.

3. Taşkın, O., Korucu, T., 2014. Kahramanmaraş İli Güneş Enerjisi Potansiyeli ve Kullanım Olanakları, Tarım ve Doğa Dergisi, 17(4), 12-19.

4. Bakırcı, K., 2007. Yatay Yüzeye Gelen Global Güneş Işınımının Tahmini, Isı Bilimi ve Tekniği Dergisi, 29(2), 53-58

5. Kallioğlu, M.A., Ercan, U., Karakaya, H., Durmuş, A., 2017. Adıyaman İli'nde Yatay Düzleme Gelen Global Güneş Işınım Değerlerinin Ampirik Modeller ile Geliştirilmesi, Fırat Üniversitesi Mühendislik Bilimleri Dergisi, 29(1), 151-159.

6. Karaca, Ü.B., Uçar, S., 2018. Konut Çatı ve Cephelerinde Farklı Fotovoltaik Sistem Uygulamalarının Değerlendirilmesi, Trakya Üniversitesi Mühendislik Bilimleri Dergisi, 19(2), 65-76. 
7. Akarslan, E., Hocaoğlu, F.O., Rüzgar Hızı Verilerinin Yeni Bir Yaklaşım ile Modellenmesi, Afyon Kocatepe Üniversitesi Fen ve Mühendislik Bilimleri Dergisi, 19(1), 121-128.

8. Mert, İ., Karakuş, C., Peker, F., 2014. Antakya Bölgesi Rüzgar Karakteristiğinin İncelenmesi, Dümf Mühendislik Dergisi, 5(1), 13-22.

9. Ozgoren, M., Bilgili, M., Sahin, B. 2012. Estimation of Global Solar Radiation Using ANN Over Turkey. Expert Systems with Applications, 39(5), 5043-5051.

10. Koç, A., Aksal, M.E., Güneş Enerjisinin Taşıtlarda Kullanımı ve Kırıkkale Üniversitesi Güneş Enerjili Araç Projesi Örneği, Uluslararası Mühendislik Araştırma ve Geliştirme Dergisi, 4(2), 15-20.

11. Çöteli, M.G., 2012. Kültürel Peyzajın Korunması ve Sürdürülebilir Kentsel Gelişmenin Yaratılması Yönünde Bir Politika Önerisi, Erciyes Üniversitesi Sosyal Bilimler Enstitüsü Dergisi, 1(32), 35-74.

12. Üstün, İ., Karakuş, C., Yağlı, H., 2020. Empirical Models for Estimating the Daily and Monthly Global Solar Radiation for Mediterranean and Central Anatolia Region of Turkey; International Journal of Global Warming, 20(3), 249-27.

13. Al-Najideen, M.I., Alrwashdeh, S.S., 2017. Design of a Solar Photovoltaic System to Cover the Electricity Demand for the Faculty of Engineering-Mu'tah University in Jordan. Resource-Efficient Technologies, 3(4), 440-445.

14. Atmaca, İ., Yiğit, A., 2010. Güneş Enerjisi, Alfa Aktüel Yayınları, 43-46, Ankara.

15. Emeksiz, C., 2019. The Estimation of Diffuse Solar Radiation on Tilted Surface Using Created New Approaches with Rational Function Modeling. Indian Journal of Physics, $1-12$.

16. Tırıs, M., Tırıs, Ç., Erdallı, Y., 1997. Güneş Enerjili Su Isıtma Sistemleri. Tübitak Marmara Araştırma Merkezi Enerji Sistemleri ve Çevre Araştırma Enstitüsü, 61, Gebze-Kocaeli.

17. Mert, İ., Karakuş, C., 2015. Antakya Bölgesinde Rüzgâr Gücü Yoğunluğu ve Rüzgâr Hızı Dağılımı Parametrelerinin İstatistiksel Analizi, Politeknik Dergisi, 18(1), $35-42$.
18. İlhan, A., Bilgili, M., Şahin, B., 2014. Efficiency Analysis of an Installed Wind Farm, Çukurova Üniversitesi Mühendislik-Mimarlık Fakültesi Dergisi, 30(1), 133-140.

19. Green, MA., Hishikawa, Y., Warta, W., 2017 Solar Cell Efficiency Tables (version 50), Progress in Photovoltaics: Research and Applications, 25(7), 668-676.

20. Adam, A.D., Apaydin, G. 2016. Grid Connected Solar Photovoltaic System as a Tool for Green House Gas Emission Reduction in Turkey. Renewable and Sustainable Energy Reviews, 53, 1086-1091.

21. Apak, S., Atay, E., Tuncer, G., 2017. Renewable Hydrogen Energy and Energy Efficiency in Turkey in the $21^{\text {st }}$ Century. International Journal of Hydrogen Energy, 42(4), 2446-2452.

22. Bilgili, M., Ozbek, A., Sahin, B., Kahraman, A., 2015. An Overview of Renewable Electric Power Capacity and Progress in New Technologies in the World. Renewable and Sustainable Energy Reviews, 49, 323-334.

23. Yağlı, H., Koç, Y., Koç, A., Görgülü, A., Tandiroğlu, A., 2016. Parametric Optimization and Exergetic Analysis Comparison of Subcritical and Supercritical Organic Rankine Cycle (ORC) for Biogas Fuelled Combined Heat and Power (CHP) Engine Exhaust Gas Waste Heat. Energy, 111, 923-932.

24. Yağlı, H., Karakuş, C., Koç, Y., Çevik, M., Uğurlu, İ., Koç, A., 2019. Designing and Exergetic Analysis of a Solar Power Tower System for Iskenderun Region. International Journal of Exergy, 28(1), 96-112.

25. Etier, I., Ababneh, M., Tarabsheh, A.A., 2011. Simulation of a $10 \mathrm{~kW}$ Photovoltaic System in Areas with High Solar Irradiation. American Journal of Applied Sciences, 8(2), 177.

26. Rai, A., Shrivastava, A., Jana, K.C., Tripathi, S., Agrawal, A., 2019. Feasibility Analysis of $100 \mathrm{~kW}$ Solar Plant for Chandigarh, India. In IOP Conference Series: Materials Science and Engineering 594(1), 1-5.

27. Kumar, B.S., Sudhakar, K., 2015. Performance Evaluation of $10 \mathrm{MW}$ Grid Connected Solar Photovoltaic Power Plant in India. Energy Reports, 1, 184-192. 